\title{
Minimal Requirements for an Effective Antiretroviral Treatment in Burma Odile Picard ${ }^{* \ddagger}$
}

\author{
Address: Dermatology and infectious disease, WHO consultant, Medical adviser for Total company; Policlinique Saint Antoine Hospital, Paris, \\ France \\ Email: Odile Picard* - odile.picard@sat.ap-hop-paris.fr \\ * Corresponding author $\ddagger$ Presenting author
}

from 2005 International Meeting of The Institute of Human Virology Baltimore, USA, 29 August - 2 September 2005

Published: 8 December 2005

Retrovirology 2005, 2(SuppI I):SI 25 doi:I0.I I86/I742-4690-2-SI-SI 25

The availability of the Antiretroviral (ARV) generic formulations since 2000 has increased dramatically the demand to access care and ARV drugs in the developping countries. Most of the subsaharian African and Asian countries which reported an epidemic have started to benefit from the various international supports.

Although there is a global consensus among the developped countries to make the ARV access easier for the developping countries, the frequent lack of sustained structures and well trained medical teams in addition to the lack of facilities are at high risk of emergence of resistant viral strains and compromission of the expected benefits.

In Burma the ARV implementation and scaling up have considered the possible mechanisms to decline the risk of emergence of a rapid resistance to the ARVs.

Burma one of the poorest country of the world has 50 millions of inhabitants. The UNAIDS estimates that the prevalence of the HIV infection is between 2 and 3\% of the global population. It is the third country of the South East Asian region (SEAR) in term of prevalence after Cambodia and Thailand.

The mix of high level of poverty, low awareness, poor health care, low political involvement, and total lack of governmental funds dedicated to this infection led the few skills to collaborate closely to set up a comprehensive programme aimed at fighting HIV/AIDS in this country prevented from accessing to most of international supports because of the political sanctions.
The french government signed an agreement in 1996 with the Burma's medical school to traine MDs in France for HIV/AIDS. 6 out of them have already been trained. The french oil company Total joined this programme in 2004 to provide medical scholarships. The 7th $\mathrm{MD}$ that the Total company has supported is the first Burma's peadiatrician trained especially for HIV/AIDS in children in Paris. After their return, these medical leaders have been posted in the 2 referral HIV/AIDS departments implemented in the 2 main cities (yangon and Mandalay) with the tecbnical support of WHO.

The Yadana company operated by Total in Burma has provided the financial support for the purchase of the ARVs which are ordered by WHO to avoid any custom fees, to ensure a regular supply and avoid shortages.

The recipient for the Total funds is the Union: an Int'NGO well implemented in numerous developping countries in charge of Tuberculosis (TB). TB is the most frequent infection encountered in HIVpatients and occurs at any time of the disease progression. This choice is a major contribution, since it has provided for the first time the opportunity to detect and treat HIV patients at an earlier disease stage. Up to now the government allowed to perform the HIV testing only in patients with evident clinical diagnosis of AIDS. The benefit of the ARV treatment started at a late disease stage is very limited compared to the one when started at an earlier stage. This earlier HIV testing possibility is the first step toward the voluntary testing in asymptomatic people who just whish to know their own status.

The HIV testing center has been implemented for the first time outside the walls of the AIDS center in the TB center. 
The test kits are provided by UNAIDS. It is the first time that the test is done anonymously in in a public place.

The setting for the programme is the General Hospital in Mandlay, the second city of the country. All the criteria required to start the programme are met at this place. The patients are monitored by the MDs trained in France. The organization of the management of the patients has been set up by the Union which delivers the drugs to the hospital, supports the cost of the laboratories facilities as well as the cost of the management of the opportunistic infections. 2MDs from this IntNGO specialized in TB and in HIV in the developping countries are responsible for this program.

This is the first free access to the ARVs and to the care for HIV infection in a public hospital in this country.

The anonymous testing (approved by the government), the monitoring of the patients by the well trained MDs, the management of the programme performed by the MDs of the Union, the funds provided by Yadana company, and the support of WHO is an exemple of a global commitment.

One major objective of the programme is to limit the resistant viral strains which should start in Burma in patients followed up in the private sector where the drugs prescribed : monotherapy, bitherapy or tripletherapy are related to the shortages and supplies, to the variable medical knowledge and to the patient's financial resources. The success of this programme should drive the few thousands patients followed up in the private sector to the public sector providing since recently confidentiality and free access to the ARV treatment and care.

This programme is in the frame of the WHO $3 \times 5$ initiative and contributes to the sustained development.

This rare example of a synergistic and close collaboration between different structures should help to find additional funds to join the programme and expand it to other hospitals in Burma.

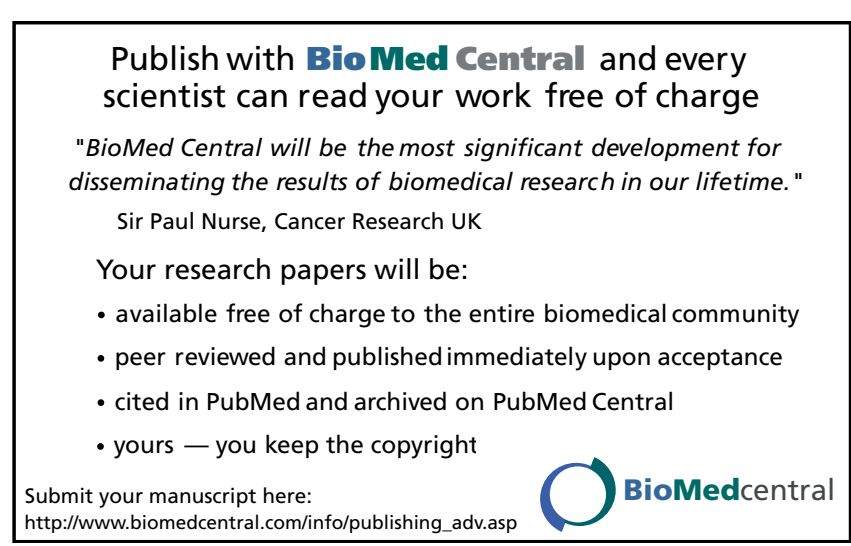

Page 2 of 2

(page number not for citation purposes) 